\title{
Cloacal reconstruction after a complex treatment of perineal haemangioma in a variant of PELVIS syndrome
}

\author{
Algirdas Zalimas" ${ }^{*}$, Gintas Posiunas², Sigitas Strupas², Ramunas Raugalas³, Juozas Raistenskis ${ }^{4}$
} and Gilvydas Verkauskas ${ }^{2}$

\begin{abstract}
Background: PELVIS is an acronym defining the association of perineal hemangioma, malformations of external genitalia, lipomyelomeningocele, vesicorenal abnormalities, imperforate anus and skin tag. Eleven cases have been reported according to the Orphanet data. Acronyms of LUMBAR and SACRAL syndrome have been used and most probably represent a spectrum of the same entity. Very little is known about the success and timing of cloacal reconstruction after the treatment of hemangioma. We present a variant of PELVIS syndrome and discuss the possibilities and optimal timing of surgical reconstruction.
\end{abstract}

Case presentation: Female infant was born with persistent cloaca and multiple hemangiomas of genitals, perineal area and left thigh. Colostomy was performed after birth. In order to treat hemangioma and to make the reconstruction of cloaca possible, corticosteroid treatment orally and multiple laser treatments were performed alternating Nd:YAG laser and pulsed dye laser therapy. Cystoscopy confirmed hemangiomatosis in the mucosa of the common channel, bladder neck and septate vagina. Oral propranolol treatment was started at the age of 18 months and continued for 1 year. It induced rapid improvement of hemangiomas. Two more pulsed dye laser treatments were performed to remove residuals of hemangiomas from the perineum and genital area. Posterior sagital reconstruction by separation of the rectum, mobilization of urogenital sinus and vaginal reconstruction was performed with no major bleeding at the age of 4 years. Postoperatively, after a period of progressive rectal dilatation colostomy was closed. Girl is now 6 years old, dry day and night without residual urine and normal upper tracts. Rectal calibration is normal, fecal continence is still to be evaluated but constipation is easily manageable. CT of the spine and the perineum showed sacral dysplasia and spina bifida with lumbo-sacral lipoma and tethering of terminal filum without neurological deterioration at the moment but requiring close neurological monitoring.

Conclusions: Large perineal hemangiomas are commonly associated with extracutaneous abnormalities. Successful reconstructive surgery is possible after significant reduction of hemangioma by complex treatment.

Keywords: Perineal hemangioma, PELVIS syndrome, Cloaca, Laser treatment, Reconstruction

\footnotetext{
* Correspondence: algis.zalimas@gmail.com

${ }^{1}$ Faculty of Medicine, Vilnius University, M.K. Ciurlionio Street 21, 03101

Vilnius, Lithuania

Full list of author information is available at the end of the article
}

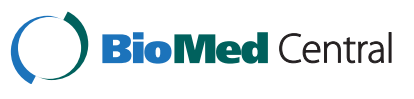

(c) 2015 Zalimas et al. Open Access This article is distributed under the terms of the Creative Commons Attribution 4.0 International License (http://creativecommons.org/licenses/by/4.0/), which permits unrestricted use, distribution, and reproduction in any medium, provided you give appropriate credit to the original author(s) and the source, provide a link to the Creative Commons license, and indicate if changes were made. The Creative Commons Public Domain Dedication waiver (http://creativecommons.org/publicdomain/zero/1.0/) applies to the data made available in this article, unless otherwise stated. 


\section{Background}

Infantile hemangiomas are sometimes complicated and associated with systemic malformations. PELVIS is an acronym defining the association of perineal hemangioma, malformations of external genitalia, lipomyelomeningocele, vesicorenal abnormalities, imperforate anus and skin tag [1]. Eleven cases have been reported according to the Orphanet data. Acronyms of LUMBAR and SACRAL syndrome have been used and most probably represent a spectrum of the same entity. Very little is known about the success of surgical reconstruction of anomalies complicated by haemangioma in these cases.

We report the 2 years follow-up results of cloacal reconstruction in a girl with PELVIS syndrome. The manuscript was performed with the approval of the Bioethics Committee of the Childrens Hospital, affiliate Vilnius University Hospital Santariskiu clinics and is in compliance with the Helsinki Declaration.

\section{Case presentation}

Female infant was born with persistent cloaca and multiple hemangiomas of genitals, perineal area and left tight (Fig. 1). Colostomy was performed after birth. During the first month of life aggressive proliferation of hemangiomas was observed. Combined treatment was administered: corticosteroid treatment $15 \mathrm{mg}$ per day orally and laser therapy by Nd:YAG laser $1064 \mathrm{~nm}$ ice cube method on hemangiomas of the perineal area and pulsed dye laser therapy $595 \mathrm{~nm}$ on hemangiomas of left thigh. After 2 months the dose of prednisolone was reduced to $5 \mathrm{mg}$, but proliferation of hemangiomas was observed and laser therapy was performed again by long pulse Nd:YAG laser on genitals and pulsed dye laser therapy on perineal area and left thigh. In order to make the reconstruction of cloaca possible, laser treatments were repeated by pulsed dye laser 4 more times. Good

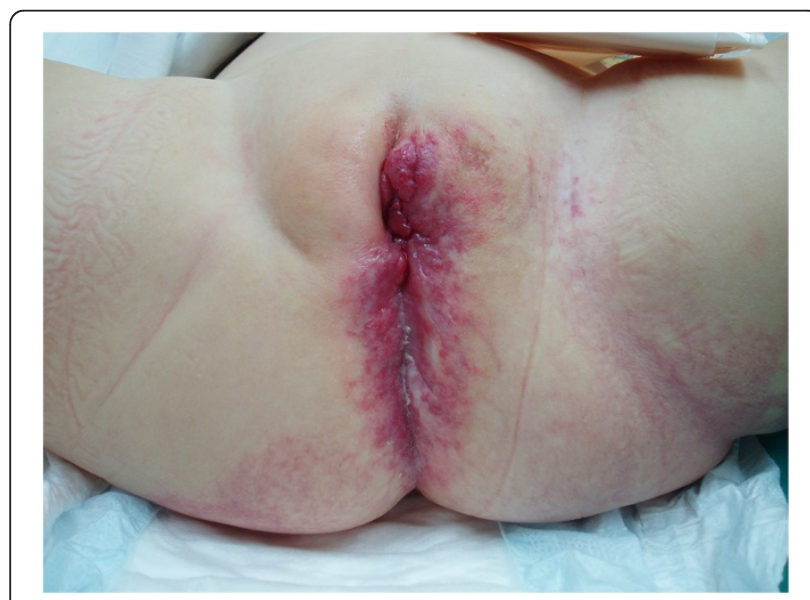

Fig. 1 Residuals of hemangiomas of genitals, perineal area and left thigh at 3 years of age effect was observed externally but cystoscopy showed prominent hemangiomas in the mucosa of cloaca and the bladder neck. Oral propranolol treatment was administered $2 \mathrm{mg} / \mathrm{kg}$ per day at the age of 18 months, followed by rapid improvement of hemangiomas. Pulsed dye laser treatment was performed twice more during 4 month period removing residuals of hemangiomas from the perineum and genital area. Propranolol treatment was continued for 8 months until almost no hemangiomas were seen and reconstructive operation was considered to be safe. Posterior sagital reconstruction by separation of the rectum, mobilization of urogenital sinus and vaginal reconstruction was performed with no major bleeding at the age of 4 years. Postoperatively, after a period of progressive rectal dilatation colostomy was closed. Girl is now 6 years old. Urinary continence was evaluated by a diary and the ultrasound of kidneys and the bladder. She is urinary continent: dry day and night, voiding without residual urine in the bladder and no dilatation of the upper tract. Fecal continence is still to be evaluated but bowel movements are regular with short periods of constipation manageable with laxatives and/or enemas occasionally. CT of spine and the perineum showed sacral dysplasia and spina bifida with lumbo-sacral lipoma and tethering of terminal filum without neurological deterioration at the moment but requiring close neurological monitoring.

\section{Discussion}

Due to the extreme rarity there is no treatment algorithm of this syndrome. Every individual case dictates timing and the choice of therapy for the best long term outcome. Congenital anomalies of a urogenital tract, like persistent cloaca, are by itself associated with a great chance of poor functional outcome even after successful surgical procedure. The association of a disfiguring haemangioma in the area of reconstruction gives first impression of poorer prognosis.

The recent discovery of propranolol effectiveness and the improved employment of Laser technologies may improve the perspective for these children.

Léauté-Labrèze et al. reported the antiproliferative effect of propranolol on infantile hemangiomas on June 2008 [2]. Recent meta-analysis demonstrated the corticosteroid studies to have a pooled response rate of $69 \%$ versus the propranolol response rate of $97 \%$ $(p<0.001)$ [3]. Propranolol introduction in the treatment complex of our case also seemed to induce marked improvement.

Laser therapy for proliferating hemangiomas is controversial. One study have demonstrated good results with either the $585 \mathrm{~nm}$ or $595 \mathrm{~mm}$ pulsed-dye laser on superficial but not deep infantile hemangiomas [4]. Other studies showed no difference between complete and 
nearly complete clearance with early laser treatment compared to observation alone at 1 year of age [5]. Severe ulceration and scarring have been reported as an adverse event, particularly when treating segmental hemangiomas during the proliferative phase.

With our choice of Nd:YAG laser $1064 \mathrm{~nm}$ ice cube method and pulsed dye laser therapy $595 \mathrm{~nm}$ we didn't observe complications and the growth of hemangiomas has stopped and regression induced. Combined treatmentsystemic therapy and multiple laser applications seems to be the most effective treatment.

Reconstructive operation mobilizing rectum and urogenital sinus and performing genitoplasty by posterior sagital approach in this case requires extensive dissection and mobilization of delicate structures what could be harassed by bleeding [6]. That is why surgery which is advocated at the age from 6 months to 1 year was postponed to 4 years of age. It allowed carrying out the difficult surgery successfully with minimal blood loss and no long term complications.

\section{Conclusion}

we support the current evidence of common association between large perineal hemangiomas and extracutaneous anomalies. Delaying reconstructive surgery until the safe reduction of hemangiomas by complex treatment does not seem to worsen long term functional and cosmetic results.

\section{Consent}

Written informed consent was obtained from the parent of the patient for publication of this Case report and any accompanying images. A copy of the written consent is available for review by the Editor of this journal.

\section{Competing interests}

The authors declare that they have no competing interests.

\section{Authors' contribution}

AZ: data collection, literature review and manuscript preparation; Others: patient treatment, revising manuscript critically for important intellectual content, have made substantial contributions to conception and design. All authors are supported by the Medical Faculty of Vilnius University. All authors read and approved the final manuscript.

\section{Authors' information}

Not applicable.

\section{Acknowledgements}

The authors gratefully acknowledge the contributions of all the pediatric surgery, pediatric urology and neonatal intensive care units of Childrens Hospital, affiliate of Vilnius University Hospital Santariskiu Klinikos for the care and treatment of this patient.

\section{Author details}

${ }^{1}$ Faculty of Medicine, Vilnius University, M.K. Ciurlionio Street 21, 03101 Vilnius, Lithuania. ${ }^{2}$ Children's Surgery Centre, Faculty of Medicine, Vilnius University, Santariskiu Street 7, 08406 Vilnius, Lithuania. ${ }^{3}$ Department of Neurology and Neurosurgery, Vilnius University, Santariskiu Street 7, 08406
Vilnius, Lithuania. ${ }^{4}$ Department of Rehabilitation, Physical and Sports Medicine, Vilnius University, Santariskiu Street 7, 08406 Vilnius, Lithuania.

Received: 6 June 2014 Accepted: 1 October 2015

Published online: 08 October 2015

References

1. Girard C, Bigorre M, Guillot B, Bessis B. PELVIS syndrome. Arch Dermatol. 2006;142:884-8.

2. Léauté-Labrèze C, Dumas De la Roque E, Hubiche T, et al. Propranolol for severe hemangiomas of infancy. N Engl J Med. 2008;358(24):2649-51.

3. Izadpanah A, Izadpanah A, Kanevsky J, Belzile E, Schwarz K. Propranolol versus Corticosteroids in the treatment of infantile hemangioma: a systematic review and meta-analysis. Plast Reconstr Surg. 2013;131(3):601-13.

4. Kolde G. Early pulsed-dye laser treatment of childhood haemangiomas. Lancet. 2003;361(9354):348-9.

5. Michel JL. Treatment of hemangiomas with $595 \mathrm{~nm}$ pulsed dye laser dermobeam. Eur J Dermatol. 2003;13(2):136-41.

6. Levitt M, Peña A. Cloacal malformations: lessons learned from 490 cases. Seminars in Pediatric Surgery. 2010;19:128-38.

\section{Submit your next manuscript to BioMed Central and take full advantage of:}

- Convenient online submission

- Thorough peer review

- No space constraints or color figure charges

- Immediate publication on acceptance

- Inclusion in PubMed, CAS, Scopus and Google Scholar

- Research which is freely available for redistribution 